\title{
Designing with Information and Empathy: Delivering Human Information to Designers
}

\section{Chris McGinley and Hua Dong Brunel University, Uxbridge, UK}

ABSTRACT Current demographic trends such as increasing ethnic diversity and the ageing population indicate the importance for designers to appreciate and assess a wide variety of human capabilities, needs and wants.

Work is being undertaken within the Inclusive Design Research Group to investigate how one might effectively communicate a wide range of people-based information, not only meeting designer's data requirements but also enhancing empathy with those being considered. A real-world case study is described to illustrate how rich user data in its many forms (that is, 'human information' as categorized by the authors) was captured and communicated to designers. 
This research is being carried out towards the development of an online resource which will help designers organize and interrogate issues relating to end users more effectively during the design process, and assist them in forming new connections and insights at the front end of concept creation.

KEYWORDS: empathy, human information, tools, resources, communication

\section{Introduction}

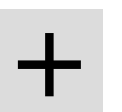

User engagement is becoming increasingly commonplace in design discourse especially in service design, the information extracted being broad and varied, and results often unpredictable and difficult to replicate. Ideally information for design would always be obtained through interaction with the target users throughout the design process, allowing the designer to develop more thorough understanding and empathy, but time and money restrictions within a typical design development process often result in minimal user engagement (Cassim, 2010).

A key requirement of our research is to identify what designers consider to be useful human information for design development. From an engineering or scientific standpoint this might be anthropometrics. From a marketing perspective it might fall into trends and consumer behaviour. For a designer it can often encompass these and a great deal more, from primary data they might collect themselves (such as measurements, quotes, pictures, recordings, prototype testing results, and so on), to secondary data they are often given with the initial brief or collect throughout development (for example, anthropometric data, academic papers, newspaper articles, case studies). There is potential to present richer stories through utilizing a variety of sources, both conventional and unconventional, to support a people-centred approach to design.

\section{Existing Approaches to Human Information}

Data is used in varying ways through the course of a design project, where the need for information goes through peaks and troughs during the designing process as priorities in the development change (McGinley and Dong, 2009). However, many designers perceive the prospect of delving into established data resources and embracing research, especially in relation to time, complexity and organization required, as stifling. They often prefer to focus on current trends and advances, and the creation of new things (Frayling, 1993).

Designers take pride in their intuition, curiosity and observations of everyday life and the products that fill this space, with hunches and instinct often being large drivers of their work. Given that in 
the United Kingdom a typical designer is aged thirty-something, Caucasian and often male (Design Council, 2010a), this approach can at times result in a limited understanding of more diverse user groups and their needs and habits. The experiences of the designer regularly differ from those that they design for, hence gaining insights into the experiences of diverse groups can be invaluable in understanding users and evaluating designs (Ostroff, 2003). When designers are unable to obtain direct input from end users, they become dependent upon indirect sources such as available literature to look beyond their own understanding and experiences. Highly visual by the very nature of their profession, designers might take different approaches to data relative to other professions. Lofthouse finds that 'designers are motivated by visual communication and like information to be presented with maximum use of graphics (pictures and colour) and minimal text', also stating that designers 'ask for nuggets of information (short pieces of text) that can be easily digested' (Lofthouse, 2006). These are the kinds of considerations that are essential to encourage information utilization, elements which can inspire, inform, and communicate in a designer-friendly way.

\section{Information Barriers}

Information from a client can vary immensely, often leaving the task of interpretation and refinement to designers or managers to edit and 'cherry-pick' for detail that is felt to be of merit to the design problem. To supplement this, designers will refer to previous experiences and projects, and consult a wide variety of tried and tested sources they have at their disposal; they have little time to devote to reading new materials (Goodman et al., 2007). In the early exploratory stages, designers will use a combination of resources in order to inform and inspire their design processes; however, a great deal of this is opportunistic and serendipitous with new human information being generated for each new project.

Another significant barrier to existing information use is access to design relevant information presented in a design relevant manner. Information saturation is often a problem when designers consider, for example, conventional anthropometric resources, which often leave the reader cold and uninspired (Patnaik, 2009). In striving for the new and innovative there is little more off-putting than to be confronted with data that is outdated, such as is the case in the majority of anthropometric data collections in otherwise informative reading list standards. Additionally such texts are frequently further exposed as dated through the lack of contemporary objects they contain (Butters and Dixon, 1998). Dislocated body parts lacking human qualities are unlikely to inspire empathy in designers, nor will sterile environments encourage those being studied to act as they would naturally in more familiar surroundings. Contextual information in realistic settings would create more accurate and appropriate 
insights, and remind designers of the real people they are designing for (Ylirisku and Buur, 2007).

Although a huge amount of anthropometric data currently exists, and is at times referenced by designers, presenting such information in a format that designers desire is no easy task. It has been suggested that optimal tools for designers should be 'simple, intuitive, highly visual' and 'fast, easy to learn and easy to work with' (Nickpour and Dong, 2008). User images (such as photographs, drawings, handwriting and so forth) are more effective than words for delivering true feelings and concepts to a designer (Lee et al. , 2000). Therefore, including these formats could be an effective means of instilling greater empathy and encouraging more extensive use of human information.

In a world of 'information overload' and 'shortening attention spans' (Swayne, 2006), designers are stretched to source original and appropriate data which proves time-consuming and inconvenient, often resulting in a diluted and fuzzy knowledge resource, particularly if the client has not emphasized or provided user input as part of the brief. User input can consequently become a secondary requirement to the project, and is left under-explored.

\section{Data and Empathy}

Designers often feel mistrust towards data that has already been through a process of interpretation (Restrepo, 2004), preferring to gather their own primary data through exploration. Typically designers' skills and knowledge in the professional realm come from experience-based learning, building a knowledge base of past developments and user responses in relation to them.

However, individuals cannot be generalized, and assumptions can be hugely problematic when creating empathic and wide-reaching design solutions, hence it is essential to consider the individual and the level of diversity, or at least touch upon the outer limits of the potential user groups (for example, young-old; able-disabled). Many designers try to consider a range of users, but are likely to generalize and design for the 'average'. The conscientious designer may attempt to design to accommodate a range of end users from $5^{\text {th }}-95^{\text {th }}$ percentile; this might even be taken further by the very diligent designer to accommodate $1^{\text {st }}-99^{\text {th }}$ percentile. Molenbroek and de Bruin (2005) produced a useful visual summary with graphs illustrating common approaches for anthropometric design types (see Figure 1), many of which are well integrated into conventional design processes. However, going beyond these into the realm of human understanding and empathy is crucial for effective design outcomes, as considering individuals as merely numbers and measurements is limited, no matter how thoroughly it is carried out. Designers complain that marketing data gives them no inspiration or feeling for the user's situation and experience (Sleeswijk Visser and Kouprie, 2008). It has been shown that considering 'extreme' or 'expert' 


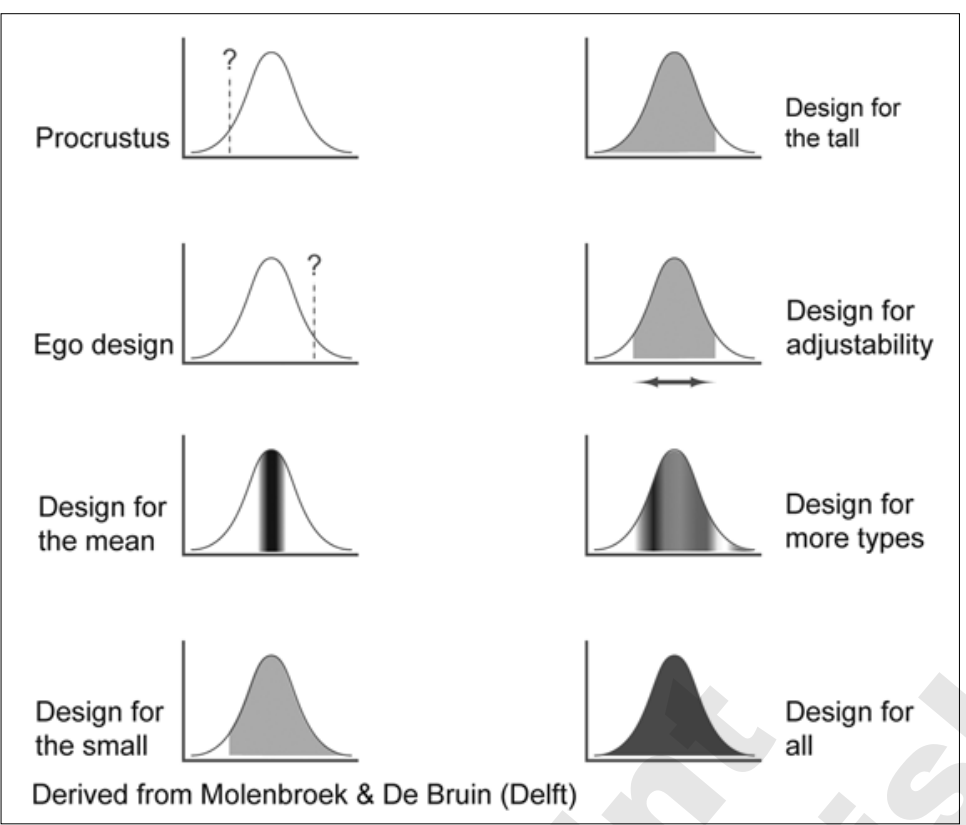

users in the design process, particularly in the early exploratory and conceptual stages, can create very interesting and inspiring lateral thinking (Dong et al., 2005; Fulton Suri and Marsh, 2000).

'Product designers want to have as much human factors inspiration as possible in the conceptual design phase of a project' (Fulton Suri and Marsh, 2000). Indeed designers need to be as knowledgeable as possible about those they intend to design for including some understanding of anthropometrics and biomechanics; however, they cannot be expected to be fully versed in all ergonomic techniques and need to be aware of their own limitations (McDonagh and Thomas, 2010). Traditionally knowledge gaps were addressed through collaborations with human factors experts. However, when involving such experts in the design process, they would also be expected to provide and interpret user data for the project (Stanton and Young, 1998). Where the data is specialized, human factors and ergonomics specialists can form part of multidisciplinary teams to address the specialist knowledge needs, and instil this information into the design process. However, what must not be neglected, and what should be a key skill in the designers' armoury is the ability to use this information, while continuing to design with empathy and to have sensitivity to the warmer values of products.

There is a desire for raw data in a format that is condensed down to be design-relevant, allowing designers to quickly glean overarching themes, but to also allow depth for 'discovery' of project significant insights (McGinley and Dong, 2009).

\section{Figure 1}

Overview of anthropometric design types (reproduced after Molenbroek and de Bruin, 2005). 


\section{Figure 2}

Empathic research for inspiration (reproduced after Bontoft, 2004).

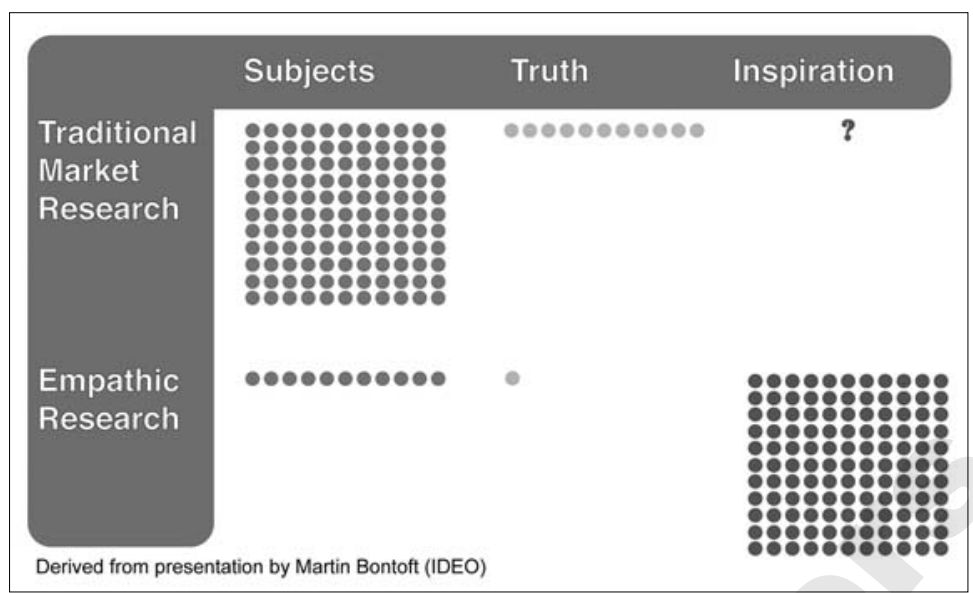

Market research often gathers and simplifies information, generalizing to assist in establishing average target profiles for consumers. Unfortunately this leads to a loss of important design relevant information that can provide human insight and inspiration. Martin Bontoft, during an internal presentation at the Helen Hamlyn Centre in 2004, presented a diagram illustrating how different approaches can produce different outputs. It describes how in traditional market research it is typical to use a large sample group from which you can establish some generalizable 'truth' (see Figure 2); however, this 'truth' when presented to designers offers very little in the way of inspiration. An alternative 'empathic' approach might involve a much smaller sample group from which less 'truth' results; however, this smaller group can be studied with more depth, and instead of answering a series of questions that only scratch the surface, conversations can take place which are far richer and can thus be more inspirational for design.

The history of product design has a limitless catalogue of designs that fall short of the necessary user criteria. Where the breakdown between user-need and design realization occurs is open to enquiry. It could be due in part to the inaccessibility of the information that human factors experts and similar produce, which may not be suitable for designers. Problems are particularly evident where the data has not originally been compiled with designers as the intended reader (for example, if the information has been compiled with a medical or scientific audience in mind); translation into design relevant understanding is both difficult and prone to error. On this basis there appears to be great potential to translate such findings and data into a format that can stimulate people-centred design, and bridge the gap between analysis and synthesis (Hasdogan, 1996). 


\section{The Need for Empathy in Design}

You need to know your user, for it is not you (IDSA, 2009).

Empathy can help a designer take a product offering beyond the purely functional, to a new level where the value to the owner is acutely greater, going beyond functionality and usability in product use into the realm of pleasure (Jordan, 1997). Some of the descriptors that Jordan uses in relation to pleasure in products are security; confidence; pride; excitement; satisfaction; entertainment; freedom and nostalgia. All of these are elements that a good designer should hope to elicit from his/her target users when considering their design needs. Further to this Weightman and McDonagh (2003) go on to describe 'supra-functional' needs, which include the emotional, spiritual, social, aspirational and cultural aspects, and recommend that when collecting data for the design process that these more difficult to grasp and communicate needs should be included.

There is a need to move away from the dry representations that exist in conventional anthropometric resources, and to bring human information to life through presenting user insights as fuller stories, conveying liveliness through visual material, and giving scope for the design audience to complete the interpretations, allowing a level of co-ownership. Presenting more than just data when trying to understand the lives of real people, a variety of strategies and techniques need to be deployed in order to get closer to a true understanding.

Understanding people is increasingly important to designers, not only to distinguish oneself from the growing global competition, but also to tap into what are very real and lucrative markets (such as the older 'grey' market). Additionally, people today are better informed through communication mediums such as the internet, and have a better understanding of what designers can and should deliver. Users are migrating from being the observed to being actively involved in the design process itself; it is essential to understand and include those being designed for and how this inclusion can be applied to design processes. Dan Formosa (2009) of Smart Design states 'the future of design rests on understanding people'.

Plowman (2003) refers to empathy as 'the altered subjectivity that can come from immersion into a particular context'. Empathy and the emotional experience of product and service use are difficult to measure, but important to appreciate for more insightful design outputs. Through the use of new resources empathy can be enhanced which in turn should help designers appreciate the emotional dimensions of user needs. The following section of the paper will describe a case study that demonstrates the process of capturing and communicating rich human information for design. 


\section{Case Study: 'Safe Ways In Glass'}

The first author of the paper was a lead researcher with Innovation RCA in the project 'Safe Ways In Glass' (SWIG). The project was commissioned by the Home Office and the Design Council as part of the Design and Technology Alliance's 'Designing Out Crime' initiative, the intention being to tackle the issue of drinking vessels and their potential to be used as a weapon in alcohol-related violence in the UK.

There are many established approaches to understanding issues holistically and eliciting physical, cognitive and emotional concerns; however, two critical limitations exist: skill and time. These constraints frequently mean 'designers are forced to rely on research reports or design briefings, in which the user is typically reduced to an abstract consumer' (Desmet et al., 2001). This was a concern considered throughout the development of the brief and briefing material for this project. The research team intended to provide information, insight and inspiration through presenting users in a raw and natural format, replicating direct contact as closely as possible. As the core team was comprised of design researchers and designers, there was an impulse to establish design criteria; however, as the goal was to define the problem and supply materials for others to use, the primary goal became the transfer of our knowledge to the designers. The researchers considered the production of user information as a design process, and in doing so produced highly visual, descriptive and immersive communications. This was all about knowing the audience and convincing them that the information was trustworthy and of good 'quality' (Wang and Strong, 1996).

\section{Purpose}

Alongside discussions with the client, a brief acts as an initial (and critical) information source for designers beginning a new project. However, design briefs are often delivered in a compact manner; with little consistency between the content and format, the accompanying reference material provided by the client can vary in quantity and quality, and rarely is it communicated in a 'designerly' way. Therefore, the purpose at this stage in the project was to create a base of information and instruction from which a complex design problem could be understood and addressed by designers. The researchers had the unusual opportunity of gathering the data and information for brief development, and 'designing' that data in order to create context and provide human insight, as well as identifying key themes and opportunities.

The research aimed to identify key issues and opportunities for the formulation of the SWIG brief and accompanying information, considering key stakeholders and diverse users from the outset. The goal of this initial phase was to understand the role of traditional glassware within a drinking culture and the many stakeholder perspectives holistically, and use these findings to create 
a comprehensive briefing document and a well-informed starting point for designers, from which they could proceed with design development.

\section{Process}

Essentially tasked with designing accessible information for designers, the researchers' approach was similar to a typical design development process, demonstrating a familiar route in order to retain credibility and producing resources appropriate for application in design development. To fully understand the nature of the problem and develop key areas for development the project ran in the sequence of exploration, communication, ideation and delivery (see Table 1).

Table 1 Studies conducted to capture requirements.

\begin{tabular}{l} 
Research scoping: identification of key areas of research. \\
Resploration \\
Research activities: literature and image review; user interviews; \\
product and material testing; sample collection. \\
Stakeholder engagement: identification of key industry influencers, \\
followed by meetings to secure 'buy-in' and support. \\
Research analysis: prioritisation of key research insights. \\
Communication \\
$\begin{array}{l}\text { Workshop planning: defining format/deliverables, and planning of } \\
\text { stimulus to allow participants to rapidly absorb research insights. } \\
\text { Creative workshop: a one day workshop aimed at generating a wide } \\
\text { range of ideas from all stakeholder persepectives for later evaluation. } \\
\text { Idea evaluation - analysis and grouping of the solutions generated } \\
\text { at the workshops, and preliminary selection of most promising. } \\
\text { Delivery of documentation and multimedia resources: compiled } \\
\text { research and workshop outputs towards brief creation and support. }\end{array}$ \\
\hline Delivery
\end{tabular}

\section{Exploration}

The research initially involved gathering printed material (such as academic papers, police reports, newspaper articles, publications of suppliers and drinks trade) on the subject. From this information key themes were identified, and experts relating to each theme were contacted. The stakeholders consulted fell into the following six key categories:

- Academic

- Law Enforcement

- Materials and Manufacture

- Users

- Industry

- Medical Profession 
In order to obtain a UK-based overview three cities were selected for the study which were felt to be appropriately representative of the issues being addressed:

- Glasgow - which imposed a glass ban in 2006 for late night licensed venues

- London - with a diverse multi-cultural populace, and strong night economy

- St Albans - having the largest ratio of pubs to head of population in the UK

Endeavouring to communicate the richness of the environment, and capture some of the sensory stimuli (for example, visual, aural), the researchers interviewed users in situ, and video, photo and audio recordings were made. Such visual material is particularly useful to the designers as it provides contextual texture relevant to the users' world (Fulton Suri, 2003). Each interview was video recorded with a 'flip' camera; these cameras were selected as they are discreet and have an interesting point of view (similar to face-to-face), which makes the playback more engaging. Additionally the small file types could be quickly uploaded onto the internet and made instantly accessible to the team, making communication of information and findings between the team more efficient.

Insights gained from the research activities led to the definition of four key insight themes:

- Industry

- Environment

- Vessel

- Users

\section{Communication}

A workshop was then organized, the intention being to create collaborative discussion between representative stakeholders from the many standpoints within the holistic picture, and reach some level of consensus as to potential and practical solutions areas, from which a brief(s) would be created. Through the course of the research a network of interested parties and industry experts was established; from these groups invited participants were then separated into three groups comprising a mixture of professions, predominantly designers, materials experts and people working in the drinks industry (from brand managers to bar staff).

Previous work in the field has underlined the need for the presentation of user data to be "quick and easy to find and use, visual and stimulating, flexible and open-ended, and relate clearly and concretely to design issues' (Goodman et al. , 2007). At the beginning of the workshop a ten-minute documentary film, directed and narrated by the researchers using video clips compiled through the 


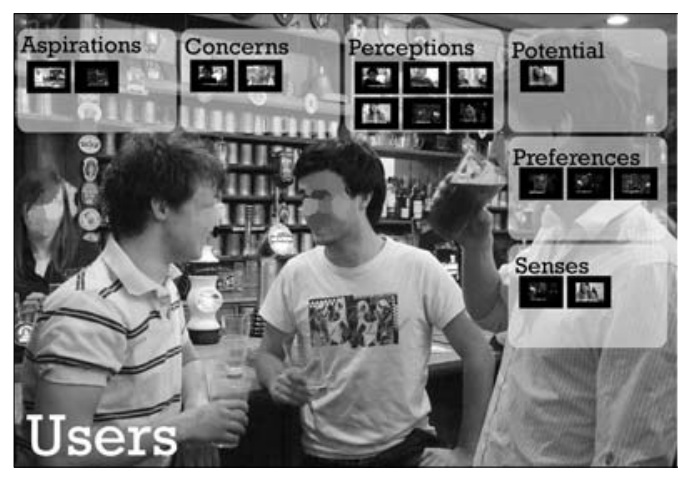

research phase was shown to the participants. The film was edited to present the issues and communicate key findings. Following this the researchers made a presentation including an introduction to interactive screen based resource boards, which communicated a variety of findings based on the insight themes. Figure 3 shows the theme of 'users'. These interactive resources allowed the workshop participants to explore multimedia resources, and presented insights into the environments and stakeholder perspectives.

Each of the insight themes became the driver for brainstorming during separate breakout sessions in relevant spaces, which were set up to stimulate discussion. For example when considering the 'users' theme the workshop attendees were provided with pint glasses and protective clothing, so they could experience the sensation of breaking the glass against a solid surface as well as getting an idea of the kind of forces and grips required to successfully break the glass. Watermelons were provided to give attendees an insight into how readily the now broken glass could slice through flesh (albeit the flesh of a fruit). Continuing on the theme, lunch was provided in a closed bar (to ensure only those attending the workshop were on the premises). This allowed the participants to fully access and explore all areas of a typical bar setting, including those they would not typically have (such as behind the bar); to inform their discussions, the bar manager was also at hand for discussions relating to the setting.

\section{Ideation}

Ideas were collected on post-its over the course of the workshop. These were grouped according to the question they addressed, and the assets of the solution, and were then distilled into 'key opportunity' areas under the three driving questions of the workshop:

1. How can glass be made safer?

2. How can alternative materials be made more appealing?

3. How can industry and consumers be persuaded to change?

\section{Figure 3}

'Users' themed interactive board. 
Finally the opportunities identified through the workshop were gathered into like categories from which those with seemingly most potential were plotted into a chart with axes criteria being 'feasibility' and 'appeal to trade and consumer'. They were rated on a simple scale of high to low. The outcome of this helped identify the key opportunities to be presented in the final briefing document.

\section{Delivery}

A twenty-page 'key insights' document was produced by the researchers, providing a summary of the research including key statistics, quotes and trends, among other issues identified. A resulting fourteen-page brief (including appendix) was released in July 2009 by the Design Council, offering the opportunity for designers to apply to be involved in 'designing the next generation pint glass', and pitch for the project.

In addition to the research documents produced to support the final briefing document, a visual mapping (see Figure 4 for sample) of the research process was constructed to communicate the journey taken, explaining and supporting the material being presented and how it was collected.

\section{Use of Research Materials and Impact on Design Process}

An interview was carried out with a member of the winning design consultancy to evaluate how the briefing and research materials were received, and how they compared to a typical project. They confirmed they were unlike anything they had previously received in terms of depth and variety, which they believed positively impacted upon the project and assisted them in their goal to 'connect with consumers'. The material was given to all the designers on their

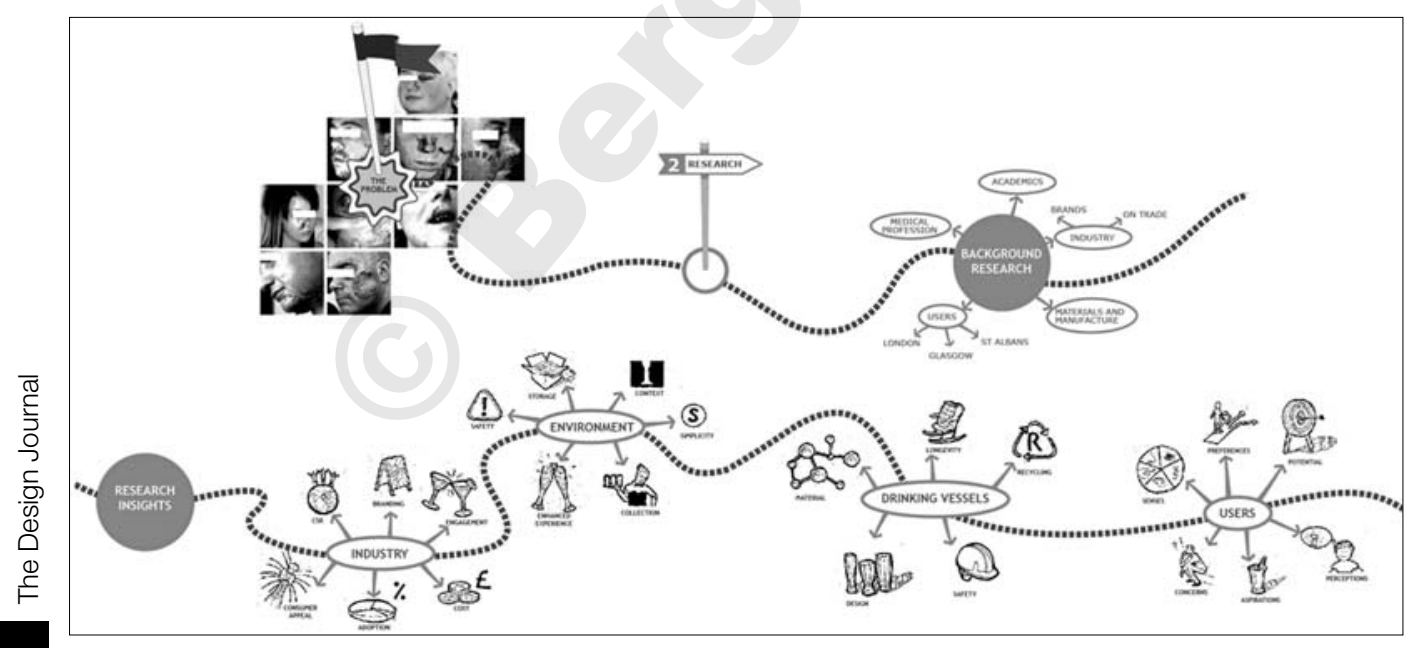

Figure 4

Mapping research journey (Credit: Innovation RCA). 
team, using it as the starting point for the project, as they felt it was 'manageable', 'stimulating' and 'interactive', describing it overall as 'a great briefing template'. Asked to describe how it differed from conventional project materials and was received by the team, they gave the following explanation: ' . . the research was all nicely ordered, so you could go into what type of stakeholder types. There was video footage, there was imagery, there were diagrams, there was data driven stuff, there were testimonials. It was all sorts. There was a real range. Different people within the creative team, and the client servicing team can latch onto and understand different types of information as well, I guess everyone has different learning approaches.'

Explaining that their design team might typically be briefed with a single image and a short description before commencing a new project, their design journey was markedly more pensive. The nature of the non-typical richness of research material made available to them encouraged them to take a more reflective approach; they stated: '... more often than not you can get into a concept phase relatively quickly when you're given a product design brief, but this one we took a lot of time to filter and do our own assessment, so what are the pros and cons of what is out there already, based on what this (the research material) taught us.'

A collection of initial concepts were developed by the design team, based on the research material provided. These concepts were assessed by a variety of key stakeholders (many of whom were identified through the research documentation), which lead to two new pint glass propositions. The two leading concepts were then prototyped and tested before being unveiled to the public during a high-profile event, which received a great deal of media attention. One of the concepts has since been through substantial further development, and at the time of writing was being trialled in UK bars (Design Council, 2010b).

\section{Discussion}

The SWIG case study acted as a test-bed for exploring the suitability of a variety of approaches and formats for human information organization and representation, and provided insights into how designers responded to the human information formats presented. It clearly demonstrated that anthropometrics are only one of many information sources relating to people which designers can draw rich insights from. Mixing more generalized information with details relating to specific individuals worked well, and helped to create richer pictures.

Although the research materials presented were praised, they were not considered as a stand-alone solution to research, as a member of the design team stated: '... hearing that, experiencing it, asking those questions, it's just slightly different. I think it will always be the case, there's no substitute for the face-to-face interaction 
yourself, and going through that experience, but the way in which this was presented and being able to get the different types of research methodology by video footage and more interactive types of research made it extremely useful'.

They discussed that they had great difficulty in arranging their own meetings with stakeholders; however, they felt such interactions were essential to their process. This need is part of empathy building and the design journey, but is also a matter of due-diligence. The designer explained that their concept generation was based on a combination of what the research materials had taught them and their own 'gut-feel'; hence, to corroborate their decisions they naturally wanted to be sure that the research was sound.

Interestingly, when they were asked to single out a particularly useful piece of information from the research, the selected piece was a provocative text description of the sensorial process of having a beer poured into a glass and presented, followed by a description of the experience of drinking from the glass. This description was created based upon statements users made about their preferences for beer being served in a glass vessel. This demonstrates the unpredictable potential of a variety of information formats; although the ineffectiveness of text-based reports was a criticism raised by the designer, they nonetheless selected a text-based description over images and video footage showing identical sequences.

A major challenge in human information communication arises in bringing the users to life for the design team in order to support 'deep understanding' (Sleeswijk Visser and Kouprie, 2008). It is all too easy to make up personas or other representations of individuals backed up with criteria a team consider to fit current trends or their own perspectives, essentially idealized (for the purpose of the exercise) fabrications. The art in the communication comes in taking a real person and condensing what he/she says and does into a useful representation of who he/she is, in such a way that a designer will want to further explore through the resources that have been provided. To be put to best effect personas and other means of relaying human information must have real life embedded within the information. Detailed information about specific people can be incorporated into human data sets to supplement new, ongoing user input; in this way the often limited and expensive direct user interaction could be most effectively prepared for having already interrogated stored human information. The information conveyed must allow designers to delve deeper, not only understanding the physiology of subjects but also getting a 'feeling' for them as people, their lives, their needs and their wants; understanding the individual point of view and how it might inspire and be applied in a more generalizable way. Human information communication can distinguish itself through the inclusion of new real people in their natural settings, with conventional data supported by empathy-enhancing footage, insights and anecdotes, raw and direct from the user. 
Without doubt, designers draw a rich tapestry of human information beyond anthropometrics from users they study, particularly in the early stages when they are less likely to be testing well formed ideas or prototypes, but instead attempting to understand the people they hope to design for. As Keinonen (2009) states, 'much of the user study methodology in design is based on understanding the implicit nature of motivations. Thus, what is mediated from the use activity to the design activity is not a set of well-explicated unquestionable and relevant needs, but a range of data that is interpreted and categorised as needs'. These interpretations are part of the creative process key to the conceptual stage of the design development. However, these collections of habits, quirks, and less obvious idiosyncrasies can very quickly lose the sharpness of detail they initially had, and become vague recollections. Means of representing, retrieving, organizing and reflecting upon this information can be invaluable, adding structure and creating a living resource that can be interactively explored and developed upon. In much the same way as the information must seem real, it also has to maintain its original meaning, so that misinterpretations can be avoided and the empathy initially felt can be maintained to some level throughout the design process (Segelstrom, 2009).

Current resources such as anthropometric publications and software do not cater for designers effectively, lacking interactivity and variety in format. For use in design, human information support could be provided as multimedia data with context and clarity, to promote trust that the data is both relevant and accurate. To promote usage by designers, human information should be stored, structured and presented through resources that retain the essential details and cues that they are looking for, in line with their design process. Beyond this, there is the question of true understanding and empathy formation, and how it is achieved through communicating human information to 'address emotional and experiential as well as functional performance issues' (Fulton Suri and Marsh, 2000).

Our intention is to produce such a human information resource, for use in collecting and structuring meaningful findings by designers and researchers in an efficient and designerly format. Through providing such a tool that offers designers a level of authorship, they can incorporate findings drawn from their own user groups into an expanding resource for user reflection, encouraging a more diversitycentred approach to design.

\section{Conclusions and Further Work}

In summary, this paper reported on how a combination of information and empathy can enhance professional design practice. It then went on to describe approaches that were taken during a design development project, to deliver human information in more stimulating ways to designers. Finally it discussed the potential for effective human information communication approaches, and 
how these might be developed towards the creation of a human information resource to support the design process.

There is currently an abundance of ergonomic and anthropometric data available; however, it is largely inflexible and difficult to access. It is clear that data on its own is not enough, it needs to be understood, and conveyed in such a way that it retains the human qualities of those it is describing, naturally building on the knowledge a designer already possesses. Even when appropriate to a design project, most data is not in a format that appeals to designers and is hence overlooked. There is scope to make use of existing data formats by communicating them in more engaging ways, supplementing them with human information that is more engaging and inspiring. A major step is talking the designers' data language to allow them to add to the story of their design development in a natural way.

Based on the understanding gained from literature review, case studies and industry workshops, we are in the process of developing a tool that will engage designers, offering insight, information and inspiration. Our intention is to create a resource that, at its most basic can be referenced and explored through a base set of people to identify more subtle criteria. However, this set will not deal in idealized averages but instead individuals, real people with real needs, including 'extreme' user groups (Dong et al., 2005) to stimulate and challenge designers to learn about new user types and use lateral thinking. It will encourage expansion of content by designers, increasing in depth and diversity with each new user included, and discouraging shallow solutions. The generalizable information stored could be used directly in projects or could help supplement and inform further interactions with stored and new participants.

We have identified that barriers currently exist which limit the incorporation of ergonomics information and other data useful for inclusive design development. 'Means of Human Information, Representation, Retrieval, Organization and Reflection' (MHIRROR) are the focus of our future work. MHIRROR will aim to deliver information in more effective and engaging ways. It will provide a platform for designers to interact with and update user-based information, as well as helping designers organize incoming information to aid reflection upon accumulated material; hence, creating a resource that provides insights and inspiration, and enhances empathy and understanding.

\section{References}

Bontoft, M. (2004). A Brief History of Design by a Non-Designer [Presentation]. Presented at Helen Hamlyn Centre, Royal College of Art, London [viewed on 23 January 2007].

Butters, L. and Dixon, R. (1998). 'Ergonomics in consumer product evaluation: An evolving process'. Applied Ergonomics, 29(1), 55-58. 
Cassim, J. (2010). 'Designing effective user interactions examples from the challenge workshops'. Proceedings of the


Hamamatsu: International Association for Universal Design.

Design Council. (2010a). Design Industry Research 2010: Executive Summary [online]. Available at: http://www.designcouncil. org.uk/Documents/Documents/Publications/Research/ DesignlndustryResearch2010/DesignIndustryResearch2010_ ExecSummary.pdf [accessed 14 May 2010].

Design Council. (2010b). Safer 'Real Glass' Pint Glasses to Start UK Trials [online]. Available at: http://www.designcouncil.org.uk/ about-us/Media-centre/Safer-real-glass-pint-glasses-to-startUK-trials/ [accessed 7 November 2010].

Desmet, P. M. A., Overbeeke, C. J. and Tax, S. J. E. T. (2001). 'Designing products with added emotional value: development and application of an approach for research through design'. The Design Journal, 4(1), 32-47.

Dong, H., Clarkson, P. J., Cassim, J. and Keates, S. (2005). 'Critical user forums: An effective user research method for inclusive design'. The Design Journal, 8(2), 49-59.

Formosa, D. (2009). 'Six real people'. Proceedings of the International Association of Societies of Design Research [online]. Available at: http://www.iasdr2009.org/ap/Papers/Special\%20 Session/Corporate\%20Design\%20Research/Six\%20Real\%20 People.pdf [accessed 14 May 2010].

Frayling, C. (1993). Research in Art and Design [Royal College of Art Research Papers], 1(1). London: Royal College of Art.

Fulton Suri, J. (2003). 'The experience evolution: Developments in design practice'. The Design Journal, 6(2), 39-48.

Fulton Suri, J. and Marsh, M. (2000). 'Scenario building as an ergonomic method in consumer product design'. Applied Ergonomics, 31(2), 151-157.

Goodman, J., Langdon, P. and Clarkson, P. J. (2007). 'Formats for user data in inclusive design'. In Stephanidis, C. (ed.), Proceedings of the $4^{\text {th }}$ International Conference on Universal Access in Human Computer Interaction: Coping with Diversity. Lecture Notes in Computer Science. Berlin, Heidelberg: SpringerVerlag, pp. 117-126.

Hasdogan, G. (1996). 'The role of user models in product design for the assessment of users needs'. Design Studies, 17, 19-33.

IDSA (2009). Designing for Humans [online]. Available at: http://www. designingforhumans.com/idsa/anthropometric_data/ [accessed 12 January 2010].

Jordan, P. (1997). 'Human factors for pleasure in product use'. Applied Ergonomics, 29(1), 25-33.

Keinonen, T. (2009). User Need - A Fuzzy Link Between Design and Use [online]. Available at: http://www.iasdr2009.org/ap/ Papers/Orally\%20Presented\%20Papers/Design\%20lssues/ 
User\%20Need\%20-\%20A\%20Fuzzy\%20Link\%20Between\%20 Design\%20And\%20Use.pdf [accessed 14 May 2010].

Lee, S. H., Harada, A. and Stappers, P. J. (2000). 'Pleasure with products: design based on Kansei'. Proceedings of the PleasureBased Human Factors seminar, Copenhagen, 11-13 April 2000.

Lofthouse, V. (2006). 'Ecodesign tools for designers: defining the requirements'. Journal of Cleaner Production, 14(15-16), 13861395.

McDonagh, D. and Thomas, J. (2010). 'Disability + relevant design: empathic design strategies supporting more effective new product design outcomes'. The Design Journal, 13(2), 180-198.

McGinley, C. and Dong, H. (2009). 'Accessing user information for use in design'. In Stephanidis, C. (ed.), Universal Access in $\mathrm{HCl}$, Part 1, HCll2009, LNCC 5614. Heidelberg: Springer Berlin, pp. 116-125.

Molenbroek, J. and de Bruin, R. (2005). 'Enhancing the use of anthropometric data'. In de Waard, D., Brookhuis, K. A., van Egmond, R. and Boersema, T. H. (eds), Human Factors in Design, Safety, and Management. Maastricht: Shaker Publishing, pp. 289-297.

Nickpour, F. and Dong, H. (2008). Designing Anthropometrics: Insights into Designers Use of People Size Data [Technical Report]. School of Engineering and Design, Brunel University.

Ostroff, E. (2003). 'Strategies for teaching and recruiting designers for an inclusive world'. In Dujardin, M. and Dua, L. (eds), Universal Design Education. Brussels, Belgium: Koninklijke Vlaamse Academie van Belgie voor Wetenschappen en Kunsten, pp. 23-39.

Patnaik, D. (2009). Innovation Starts with Empathy: The Importance of Developing Deep Connections with the People you Serve [Online]. Available at: http://designmind.frogdesign.com/articles/ the-substance-of-things-not-seen/innovation-starts-withempathy.html [accessed 12 January 2010].

Plowman, I. (2003). 'Ethnography and critical design practice'. In Laurel, B. (ed.), Design Research: Methods and Perspectives. Cambridge, MA: MIT Press, pp. 30-38.

Restrepo, J. (2004). Information Processing In Design. Delft, Netherlands: Delft University Press.

Segelstrom, F. (2009). 'Communicating through visualizations: Service designers on visualizing user research'. The First Nordic Conference on Service Design and Service Innovation. Oslo, Norway, 24-26 November 2009.

Sleeswijk Visser, F. and Kouprie, M. (2008). 'Stimulating empathy in ideation workshops'. In Simonsen, J., Robertson, T. and Hakken, D. (eds), Proceedings of the $10^{\text {th }}$ Conference on Participatory Design. Bloomington, IN: ACM Press, pp. 174-177.

Stanton, N. A. and Young, M. (1998). 'Ergonomics methods in consumer product design and evaluation'. In Stanton, N. (ed.), 
Human Factors in Product Design. London: Taylor \& Francis Ltd, pp. 21-52.

Swayne, T. (2006). Social Vision: A New Approach to Presenting Data [Online]. Available at: http://www.hhc.rca.ac.uk/resources/ publications/CaseStudies/id4223.pdf [accessed 25 May 2009].

Wang, R. Y. and Strong, D. M. (1996). 'Beyond accuracy: What data quality means to data customers.' Journal of Management Information Systems, 12(4), 5-34.

Weightman, D. and McDonagh, D. (2003). 'People are doing it for themselves'. In Forlizzi, J., Hanington, B. and Ayoob, E. (eds), Proceedings of the International Conference on Designing Pleasurable Products and Interfaces. Pittsburgh, PA: ACM Press, pp. 34-39.

Ylirisku, S. and Buur, J. (2007). Designing With Video: Focusing the User-Centred Design Process. London: Springer.

\section{Biographies}

Chris McGinley is a Scottish-born designer, researcher and writer based in London. His academic qualifications include a MEng from the University of Strathclyde and a MA from the Royal College of Art. He worked in the Helen Hamlyn Centre $(\mathrm{HHC})$, based in the Royal College of Art for five years, where he produced inclusive design solutions for companies such as GlaxoSmithKline, Osaka Gas and the Thomas Pocklington Trust. He has tutored and led workshops on people-centred design in the UK, Japan and the USA, and has exhibited graphic and product design work internationally. $\mathrm{He}$ is currently undertaking a PhD at the Human Centred Design Institute in Brunel University, where he also tutors, developing resources to help designers gain insight, inspiration and information about those they design for and with.

Hua Dong leads the inclusive design research group, and is a founding member of the Human-centred Design Institute. Her academic qualifications include a BEng and MA from Tongji University, China and a PhD from the University of Cambridge. Before joining Brunel University as a Lecturer in Design, Hua worked as a postdoctoral Research Associate at the Cambridge Engineering Design Centre and the Helen Hamlyn Centre at the Royal College of Art. She has won a number of awards for her academic achievements, essay writing, design and leadership. She is a winner of the ASME essay competition 2003, an editor of the book Design for Inclusivity (Ashgate, 2007) and a UK NESTA Crucible awardee (2008).

\section{Addresses for Correspondence}

Chris McGinley, Inclusive Design Research Group, Human Centred Design Institute, c/o Research Office, School of Engineering \& Design, Michael Sterling Building, Brunel University, Uxbridge, UB8 3PH. Tel: +44 (0) 7799388087

Email: chris.mcginley@brunel.ac.uk 
Hua Dong, Inclusive Design Research Group, Human Centred Design Institute, c/o Research Office, School of Engineering \& Design, Michael Sterling Building, Brunel University, Uxbridge, UB8 3PH.

Tel: +44 (0) 1895267254

Email: hua.dong@brunel.ac.uk

\section{Acknowledgments}

This research is supported by the Engineering and Physical Sciences Research Council Grant EP/F032145/1. The research for the 'Safe Ways In Glass' project was undertaken as a member of Innovation RCA's research team. 